\title{
The public health utility of genome-wide association study results for smoking behavior
}

\author{
Helena Furberg ${ }^{* 1,2}$, Jamie Ostroff', Caryn Lerman ${ }^{3}$ and Patrick F Sullivan ${ }^{2}$
}

\begin{abstract}
New approaches to improve smoking cessation rates are needed. In recent years, substantial progress has been made in understanding the genetics of smoking behavior, and this knowledge may eventually be used to personalize treatment for smokers. Although there are highly significant and reproducible genetic associations, none are yet ready for clinical applications. We suggest that translational research from several disciplines, including behavioral science, ethics and economics, should be performed in parallel with ongoing genome-wide association studies for smoking behavior and pharmacogenetic trials. The coordinated effort of multidisciplinary research teams will help reveal the circumstances under which we can translate genetic insights into clinical practice in the hope of reducing the burden of smoking in society.
\end{abstract}

\section{Introduction}

Cigarette smoking is the largest preventable cause of morbidity and mortality in the world. Despite best available treatments, smoking cessation remains an elusive goal for most smokers and relapse is normal. Cigarette smoking behavior is influenced, in part, by genetic factors [1]. Incorporating smoking-related genetic risk information into clinical practice has the potential to increase smoking cessation rates and improve public health. Here, we discuss the clinical implications of emerging findings from genome-wide association studies (GWASs) for smoking behavior and pharmacogenetic trials of cessation treatments. We suggest that research from multiple disciplines should be conducted in parallel to bring us closer to the goal of delivering personalized cessation treatment for smokers.

\footnotetext{
*Correspondence: FurbergA@mskcc.org

'Department of Psychiatry and Behavioral Science, Memorial Sloan Kettering

Cancer Center, 641 Lexington Ave, New York, NY 10022, USA

Full list of author information is available at the end of the article
}

\section{GWASs of smoking behavior}

Since 2007, several GWASs among individuals of European ancestry have been conducted for different smoking phenotypes, including smoking initiation (ever versus never smokers), age of smoking initiation, number of cigarettes smoked per day (CPD), nicotine dependence (based on the Fagerström test for nicotine dependence score), smoking cessation (former versus current smokers), pack-years and duration of smoking (see Supplementary Table 1 in [2]). Most recently, meta-analyses were conducted among 143,023 individuals of European ancestry [2-4]. Remarkably, whereas previous GWASs for other complex traits with far smaller sample sizes had discovered multiple novel variants, only one locus on chromosome 15 , which harbors the cluster of nicotinic acetylcholine receptor genes CHRNA3-CHRNA5-CHRNB4, has been robustly associated with CPD across multiple GWAS of smoking [2-7]. The single nucleotide polymorphism (SNP) rs1051730 was identified as being most strongly associated with CPD; each copy of the variant allele (allele frequency = 0.35 ) was estimated to increase smoking by approximately one cigarette per day and accounted for only $0.5 \%$ of the variance in $\mathrm{CPD}$ [2].

The statistical power bestowed by the tremendous sample sizes of the GWAS meta-analyses for smoking effectively exclude the potential of identifying large effects $(>1.5)$ for common allele frequencies represented on current GWAS chips. However, additional loci for smoking behavior can be identified as a result of the improved genomic coverage of newer GWAS chips and by analyses of the 1000 Genomes project, which will enable an extension of systematic GWAS methods to SNPs with 1 to $5 \%$ allele frequencies [8]. In addition, future GWASs that refine phenotypic characterization of cessation by incorporating longitudinal data on prospective quit attempts and relapses among smokers may reveal loci associated with quitting smoking. Algorithms that incorporate multiple risk variants and their interactions also may yield stronger associations for different smoking behaviors.

\section{Clinical validity of GWAS findings for smoking}

Because of their low penetrance and inability to explain more than a small fraction of observed heritability, 
individual SNPs identified in GWASs are generally regarded as lacking sufficient sensitivity, specificity and predictive value to serve as clinical markers of heightened risk of nicotine dependence and persistent smoking in the general population [9]. To translate into a clinically valid marker, a risk factor has to be very strongly associated with a trait. Ware [10] demonstrated that even a marker with an odds ratio as high as 3.58 will not perform well as a predictive test for individual patients. Although we evaluated $C P D$ as a quantitative variable in the GWAS meta-analysis [2], the observed effect size was not sufficiently large. Furthermore, whether the SNPs identified in GWASs for CPD are relevant for cessation is unclear. Although there seems to be partial overlap between some genomic regions associated with CPD and cessation [11], SNPs in CHRNA3-CHRNA5-CHRNB4 have not been associated with smoking cessation in previous GWASs [2-4].

The effect sizes of SNPs on smoking behaviors may be larger in the context of gene-environment interactions in therapeutic clinical trials (pharmacogenetics) [12]. Pharmacogenetic studies of smoking cessation therapies may help identify subgroups of smokers who respond more favorably to specific treatments and help determine their optimal dose and duration of treatment. So far, pharmacogenetic trials of smoking cessation suggest that genetic variation in nicotine metabolizing enzymes and dopamine and opioid pathways may have a role in the efficacy of nicotine replacement therapy (NRT), whereas variation in the dopamine pathway may be relevant for response to the smoking cessation drug bupropion [13].

\section{GWASs in pharmacogenetic studies}

In pharmacogenetic studies, GWASs may have even greater potential to identify loci associated with improved cessation and, in particular, rare adverse events $[12,14]$. Preliminary evidence from the first pharmacogenetic GWAS of smoking cessation [15] suggests that regions associated with successful abstinence on bupropion or NRT are not identical, supporting observations from candidate gene pharmacogenetic studies discussed above [13], but replication is required. Given the rare but serious potential psychiatric side-effects of non-nicotinic pharmacotherapies [16], GWASs of bupropion and other therapies, such as varenicline, are warranted.

\section{Future directions}

Clearly, changes in public policy, including indoor air acts, increased taxes on cigarettes and bans on tobacco product advertising, have contributed significantly to a decrease in smoking prevalence in the US [17]. However, given that the prevalence of current smokers seems to be stabilizing, and existing cessation treatments help only a fraction of smokers to quit, new tailored approaches for cessation that involve insights from genetics deserve to be considered.
Although substantial progress has been made in the genetics of smoking in recent years, more research is needed. To maximize the potential for personalized treatment for smokers, translational research from multiple disciplines should be conducted in parallel with ongoing GWASs for smoking behavior and pharmacogenetic studies of smoking cessation. Behavioral research on the uptake, understanding and consequences of genetic risk communication will increase the likelihood that future genetic testing of smoking will result in public health improvements [18] and reduce the likelihood of harm; such harm could include a lowering of the motivation to quit or of the self-efficacy for quitting, both of which could undermine quitting efforts. Research surrounding the ethical, legal and social implications of genetic research on smoking [19] will help us handle the potential discrimination against patients related to inappropriate use of their genetic information, given the known co-morbidity between nicotine dependence and other substance abuse conditions and psychiatric disorders, the possibility of pleiotropic associations and the differential prevalence of risk-conferring genotypes among different ancestries. Cost-benefit analyses of genetically tailored treatment for smoking will contribute to the feasibility of these approaches. Finally, development of genetic testing guidelines for and training of health care providers is needed to standardize care and increase their confidence in interpreting and conveying results to their patients [20].

The coordinated effort of multidisciplinary research teams that address these complex issues will help inform the circumstances under which we can translate the genetics of smoking into clinical practice in the hope of reducing the burden of smoking in our society. Until the goal of personalized cessation treatment is realized, all smokers should be encouraged to quit, regardless of genotype.

\section{Abbreviations}

CHRNA, nicotinic cholinergic receptor; CPD, cigarettes smoked per day; GWAS, genome-wide association study; NRT, nicotine replacement therapy; SNP, single nucleotide polymorphism.

\section{Competing interests}

The authors declare that they have no competing financial interests.

\section{Authors' contributions}

$\mathrm{HF}, \mathrm{JO}, \mathrm{CL}$ and PFS were involved in drafting the manuscript and have reviewed and approved the final version.

\section{Acknowledgements}

We thank Jennifer Dackor for her curation of the genome-wide association studies of smoking behavior and editorial assistance. This work was funded by the University of North Carolina Lineberger Comprehensive Cancer Center University Cancer Research Fund Award, and NCI K07 CA118412 to HF.

Author details

'Department of Psychiatry and Behavioral Science, Memorial Sloan Kettering Cancer Center, 641 Lexington Ave, New York, NY 10022, USA. ${ }^{2}$ Department of Genetics, University of North Carolina, Chapel Hill, NC 27599, USA. ${ }^{3}$ Department of Psychiatry and Annenberg Public Policy Center, University of Pennsylvania, Philadelphia, PA 19104, USA. 
Published: 27 April 2010

\section{References}

1. Rose RJ, Broms U, Korhonen T, Dick DM, Kaprio J: Genetics of Smoking Behavior. In Handbook of Behavior Genetics, 1. 1st edition. Edited by Kim Y-K. New York: Springer; 2009: 411-432.

2. Furberg H, Kim Y, Dackor J, Boerwinkle E, Franceschini N, Ardissino D, Bernardinelli L, Mannucci PM, Mauri F, Merlini PA, Absher D, Assimes TL, Fortmann SP, Iribarren C, Knowles JW, Quertermous T, Ferrucci L, Tanaka T, Bis $J$, Furberg CD, Haritunians T, McKnight B, Psaty BM, Taylor KD, Thacker EL, Almgren P, Groop L, Ladenvall C, Boehnke M, Jackson AU et al:: Genomewide meta-analyses identify multiple loci associated with smoking behavior. Nat Genet 2010, doi:10.1038/ng.571.

3. Thorgeirsson TE, Gudbjartsson DF, Surakka I, Vink JM, Amin N, Geller F, Sulem P, Rafnar T, Esko T, Walter S, Gieger C, Rawal R, Mangino M, Prokopenko I, Mägi R, Keskitalo K, Gudjonsdottir IH, Gretarsdottir S, Stefansson H, John R Thompson, Yurii S Aulchenko, Mari Nelis, Aben KK, den Heijer M, Dirksen A, Ashraf H, Soranzo N, Valdes AM, Steves C, Uitterlinden AG et al:: Sequence variants at CHRNB3-CHRNA6 and CYP2A6 affect smoking behavior. Nat Genet 2010, doi:10.1038/ng.573.

4. Liu JZ, Tozzi F, Waterworth DM, Pillai SG, Muglia P, Middleton L, de Berrettini W, Knouff CW, Yuan X, Waeber G, Vollenweider P, Preisig M, Wareham NJ, Zhao JH, Loos RJF, Barroso I, Khaw K-T, Grundy S, Barter P, Mahley R, Kesaniemi A, McPherson R, Vincent JB, Strauss J, Kennedy JL, Farmer A, McGuffin P, Day R, Matthews K, Bakke $P$ et al:: Meta-analysis and imputation refines the association of 15q25 with smoking quantity. Nat Genet 2010, doi:10.1038/ ng.572.

5. Bierut $L$, Madden PA, Breslau N, Johnson EO, Hatsukami D, Pomerleau OF, Swan GE, Rutter J, Bertelsen S, Fox L, Fugman D, Goate AM, Hinrichs AL, Konvicka K, Martin NG, Montgomery GW, Saccone NL, Saccone SF, Wang JC, Chase GA, Rice JP, Ballinger DG: Novel genes identified in a high-density genome wide association study for nicotine dependence. Hum Mol Genet 2007, 16:24-35.

6. Amos Cl, Wu X, Broderick P, Gorlov IP, Gu J, Eisen T, Dong Q, Zhang Q, Gu X, Vijayakrishnan J, Sullivan K, Matakidou A, Wang Y, Mills G, Doheny K, Tsai YY, Chen WV, Shete S, Spitz MR, Houlston RS: Genome-wide association scan of tag SNPs identifies a susceptibility locus for lung cancer at 15q25.1. Nat Genet 2008, 40:616-622.

7. Hung RJ, MCKay JD, Gaborieau V, Boffetta P, Hashibe M, Zaridze D, Mukeria A, Szeszenia-Dabrowska N, Lissowska J, Rudnai P, Fabianova E, Mates D, Bencko V, Foretova L, Janout V, Chen C, Goodman G, Field JK, Liloglou T, Xinarianos G, Cassidy A, McLaughlin J, Liu G, Narod S, Krokan HE, Skorpen F, Elvestad MB, Hveem K, Vatten L, Linseisen J, et al:: A susceptibility locus for lung cancer maps to nicotinic acetylcholine receptor subunit genes on 15q25. Nature 2008, 452:633-637.
8. Manolio TA, Collins FS, Cox NJ, Goldstein DB, Hindorff LA, Hunter DJ, McCarthy MI, Ramos EM, Cardon LR, Chakravarti A, Cho JH, Guttmacher AE, Kong A, Kruglyak L, Mardis E, Rotimi CN, Slatkin M, Valle D, Whittemore AS, Boehnke M, Clark AG, Eichler EE, Gibson G, Haines JL, Mackay TF, McCarroll SA, Visscher PM: Finding the missing heritability of complex diseases. Nature 2009, 461:747-753.

9. Kraft P, Hunter DJ: Genetic risk prediction - are we there yet? N Eng/ J Med 2009, 360:1701-1703.

10. Ware JH: The limitations of risk factors as prognostic tools. N Eng/ J Med 2006, 355:2615-2617.

11. Drgon T, Montoya I, Johnson C, Liu QR, Walther D, Hamer D, Uhl GR: Genomewide association for nicotine dependence and smoking cessation success in NIH research volunteers. Mol Med 2009, 15:21-27.

12. Guessous I, Gwinn M, Khoury MJ: Genome-wide association studies in pharmacogenomics: untapped potential for translation. Genome Med 2009, $1: 46$.

13. Lerman CE, Schnoll RA, Munafo MR: Genetics and smoking cessation improving outcomes in smokers at risk. Am J Prev Med 2007, 33:S398-S405.

14. Crowley JJ, Sullivan PF, McLeod HL: Pharmacogenomic genome-wide association studies: lessons learned thus far. Pharmacogenomics 2009 10:161-163.

15. Uhl GR, Liu QR, Drgon T, Johnson C, Walther D, Rose JE, David SP, Niaura R, Lerman C: Molecular genetics of successful smoking cessation: convergent genome-wide association study results. Arch Gen Psychiatry 2008, 65:683-693.

16. Kuehn BM: Varenicline gets stronger warnings about psychiatric problems, vehicle crashes. JAMA 2009, 302:834

17. Levy DT, Romano E, Mumford E: The relationship of smoking cessation to sociodemographic characteristics, smoking intensity, and tobacco control policies. Nicotine Tob Res 2005, 7:387-396

18. McBride CM, Brody LC: Point: genetic risk feedback for common disease time to test the waters. Cancer Epidemiol Biomarkers Prev 2007, 16:1724-1726.

19. Shields AE, Fortun M, Hammonds EM, King PA, Lerman C, Rapp R, Sullivan PF: The use of race variables in genetic studies of complex traits and the goal of reducing health disparities: a transdisciplinary perspective. Am Psychol 2005, 60:77-103.

20. Shields A, Lerman C, Sullivan P: Translating emerging research on the genetics of smoking into clinical practice: ethical and social considerations. Nicotine Tob Res 2004, 6:675-688.

doi:10.1186/gm147

Cite this article as: Furberg $\mathrm{H}$, et al.: The public health utility of genomewide association study results for smoking behavior. Genome Medicine 2010, $2: 26$ 